\title{
KEPERCAYAAN MASYARAKAT TERHADAP PENGOBATAN KOMPLEMENTER AKUPUNTUR DI PRAKTIK PERAWAT MANDIRI LATU USADHA ABIANSEMAL BADUNG
}

\author{
PUBLIC TRUST IN ACUPUNCTURE AS \\ COMPLEMENTARY MEDICATION IN PRIVATE \\ NURSE LATU USADHA CLINIC ABIANSEMAL, \\ BADUNG
}

\author{
Kadek Sri Ariyanti ${ }^{1}$, Made Dewi Sariyani ${ }^{2}$, Cokorda Istri Mita Pemayun ${ }^{3}$ \\ STIKES Advaita Medika Tabanan
}

\begin{abstract}
ABSTRAK
Latar belakang: Terapi komplementer merupakan suatu bentuk terapi non konvensional sebagai suatu bentuk pengobatan yang berasal dari berbagai sistem, modalitas dan praktik pelayanan kesehatan yang berdasarkan pada teori dan kepercayaan. Pengobatan non konvensional seringkali berhasil ketika pengobatan konvensional tidak berhasil serta memiliki efek samping yang ringan. Akupuntur merupakan salah satu terapi komplementer sebagai upaya untuk mengoptimalkan pelayanan kesehatan. Akupuntur adalah suatu cara pengobatan dengan menusukkan jarum ke titik akupuntur tubuh. Dalam merencanakan dan mengidentifikasi asuhan yang dibutuhkan oleh pasien, perlu dikaji lebih dalam, bagaimana kepercayaan masyarakat terhadap pengobatan komplementer akupuntur. Tujuan: mengetahui bagaimana terbentuknya kepercayaan masyarakat terhadap pengobatan komplementer akupuntur. Metode: Penelitian ini menggunakan metode kualitatif. Instrumen yang digunakan adalah pedoman wawancara mendalam. Pengumpulan data dilaksanakan pada Bulan Maret-Mei 2020. Informan dalam penelitian ini adalah pasien yang melakukan terapi komplementer akupuntur dengan jumlah 10 orang. Informan dipilih secara acak (randomisasi). Untuk menilai pengalaman informan, peneliti menggunakan skala likert. Hasil dan Pembahasan: Sebagian besar informan memiliki pengalaman yang sangat baik terhadap pengobatan akupuntur. Faktor internal yang berpengaruh terhadap kepercayaan masyarakat dalam melakukan pengobatan komplementer akupuntur: kepercayaan/tradisi, persepsi dan pengetahuan. Faktor eksternal: ekonomi, kebudayaan, pekerjaan, penghasilan dan dukungan keluarga. Simpulan dan Saran: Upaya promosi dan pengembangan pelayanan kesehatan komplementer akupuntur bisa dilakukan lebih efektif dan inovatif, sehingga masyarakat dapat memilih pelayanan kesehatan yang diinginkan.
\end{abstract}

Kata Kunci: Akupuntur, Kepercayaan Masyarakat, Komplementer 
Bali Medika Jurnal.

Vol 8 No 1, 2021: 1-12

ISSN : 2615-7047

DOI: https://doi.org/10.36376/bmj.v8i1

\begin{abstract}
Background: Complementary therapy is a form of non-conventional medication or treatment that comes from various systems, modalities and health care practices based on theory and belief. Non-conventional treatments are often successful when the conventional ones are unsuccessful and have mild side effects that can be detrimental to the patient. Acupuncture is a complementary therapy that works as an effort to optimize health services. Specifically, acupuncture is a method of treatment by inserting needles into acupuncture points of the body. In regards to planning and identifying the care needed by patients, it is necessary to study how public trust in acupuncture as complementary medication more deeply. Objective: This study examines how public trust are built in complementary acupuncture medication. Methods: This study uses qualitative methods. The instrument used is an in-depth interview. Data collection was carried out in MarchMay 2020. The informants in this study were 10 patients who did acupuncture therapy. Additionally, informants were selected randomly (randomization). In regards to assess the informants' experience, researchers used a Likert scale. Findings and discussion: Results and Discussion: The majority of the informants had very good experience with acupuncture treatment. Some internal factors that influence people's trust in applying complementary acupuncture medication are belief / tradition, perception and knowledge, while the external factors are economical, culture, employment, income and family support. Conclusions and Suggestions: Promotion and development of complementary health services for acupuncture can be done more effectively and innovatively. Thus, people are provided with options of the health services they prefer.

Keywords: Acupuncture, Public Trust, Complementary

\begin{tabular}{ll}
\hline Alamat Korespondensi & : STIKES Advaita Medika Tabanan \\
Email & $\begin{array}{l}\text { : ariyanthi.midwife@gmail.com, sariyani27@ymail.com, } \\
\text { mid.cokp@gmail.com }\end{array}$ \\
\hline
\end{tabular}
\end{abstract}

\title{
PENDAHULUAN
}

Alasan yang paling umum untuk mencari suatu pengobatan demi memperoleh kesembuhan adalah sakit. Berbagai teknik pengobatan non konvensional bermunculan dewasa ini, salah satunya adalah terapi komplementer. Saat ini, masyarakat banyak yang berpindah dari pengobatan konvensional ke pengobatan alternatif/komplementer. Beberapa pihak mengklaim bahwa pengobatan non konvensional seringkali berhasil ketika pengobatan konvensional tidak berhasil. Penggunan obat non konvensional juga dianggap memiliki efek samping yang ringan yang dapat merugikan pasien (Artana, 2017).

Terapi konvensional sudah terbukti secara empiris digunakan dalam penanganan pasien dan sudah digunakan oleh kalangan medis. Saat ini terapi komplementer alternatif dan tradisional digunakan sebagai pelengkap mendampingi terapi konvensional sehingga penanganan pasien menjadi komprehensif. Masyarakat terdahulu telah memiliki budaya pengobatan dengan terapi non konvensional, sehingga pengobatan konvensional telah digunakan sejak zaman dahulu. Bahkan saat ini pemerintah telah mengakui terapi non konvensional serta telah digunakan secara luas di masyarakat (Persi, 2013). 
Bali Medika Jurnal.

Vol 8 No 1, 2021: 1-12

DOI: https://doi.org/10.36376/bmj.v8i1

Salah satu terapi komplementer sebagai upaya untuk mengoptimalkan pelayanan kesehatan di rumah sakit adalah terapi akupuntur. Terapi akupuntur dapat diberikan secara terintegrasi dengan pengobatan lain atau dapat pula berdiri sendiri di rumah sakit.

Pelayanan akupunktur dapat berdiri sendiri dan berintegrasi dengan pengobatan lain yang tersedia di rumah sakit. WHO pada tahun 1979 menetepakan berbagai penyakit yang dapat disembuhkan dengan terapi akupuntur, kemudian ilmu akupunktur terintegrasi ke dalam ilmu kedokteran modern pada tahun 1991. Akupunktur mulai dikenal di Indonesia pada tahun 1963 dengan ditetapkannya RS Dr. Cipto Mangunkusumo sebagai Pilot Projek Penelitian dan Pengembangan Ilmu Akupunktur oleh Departemen Kesehehatan RI. Akupunktur adalah cara pengobatan dengan menusukkan jarum ke dalam titik akupuntur tubuh. Teknik akupunktur dapat mengurangi rasa nyeri, meningkatkan kebugaran dan mempercepat pemulihan kesehatan pasien (Saputra, 2012).

Dalam merencanakan dan mengidentifikasi asuhan yang dibutuhkan oleh pasien, perlu dikaji lebih dalam, bagaimana kepercayaan masyarakat terhadap pengobatan komplementer akupuntur. Pengalaman tentang suatu tindakan atau fenomena merupakan hal yang unik, berbeda pada masing-masing individu dan tidak dapat diukur secara kuantitatif. Klinik Latu Usadha yang berlokasi di Desa Abiansemal Badung merupakan salah satu klinik yang melayani terapi komplementer akupunktur yang sering dikunjungi oleh masyarakat. Tujuan penelitian ini adalah mengetahui bagaimana terbentuknya kepercayaan masyarakat terhadap pengobatan komplementer akupuntur di Praktik Perawat Mandiri Latu Usadha Abiansemal Badung, yang meliputi faktor internal, faktor eksternal, hambatan dan harapan masyarakat terhadap terapi komplementer akupunktur. Harapannya adalah dapat meningkatkan kualitas pelayanan kesehatan dengan mensinergikan pengobatan konvensional dan non konvensional.

\section{Manfaat Akupuntur Bagi Kesehatan}

Salah satu terapi untuk menjaga kesehatan otak adalah teknik pengobatan akupuntur. Saat ini telah ditemukan sekitar 800 lebih titik akupuntur. Namun, titik yang sering digunakan dalam terapi akupuntur hanya sekitar 150 titik (Windridge, 1999:245). Teknik pengobatan akupuntur mempengaruhi aliran bioenergi tubuh dengan cara merangsang titik akupuntur dalam tubuh. Mekanismenya yaitu melalui sistem meridian yang mempengaruhi keseimbangan korelasi antara permukaan tubuh dan organ spesifik lainnya (Saputra, 2005).

Akupuntur secara harafiah merupakan tusukan dengan jarum yang bertujuan mengalirkan energi ke dalam tubuh manusia (Kementerian Kesehatan Republik Indonesia, 2017). Terdapat beberapa fungsi meridian dalam pengobatan tradisional Cina antara lain: tempat rangsangan penyembuhan, tempat mengalirnya energy vital, tempat keluar masuk penyebab penyakit, serta penghubung bolak balik antar organ. Meridian ini mengandung titik-titik akupuntur yang dapat dirangsang dengan alat tumpul atau jari-jari tangan yang tidak menimbulkan rasa sakit dan tidak menembus bagian kulit tubuh yang ditusuk (Sukanta, 2008).

Salah satu terapi alternatif yang digunakan untuk penyembuhan kanker adalah akupuntur (Saputra, 2002). Cara kerja akupuntur adalah dengan merangsang titik-titik akupuntur pada permukaan tubuh. Akupuntur secara umum dapat 
Bali Medika Jurnal.

Vol 8 No 1, 2021: 1-12

DOI: https://doi.org/10.36376/bmj.v8i1

berfungsi untuk peningkatan sistem humorial. Beberapa hal yang harus diperhatikan dalam pemanfaatan akupuntur untuk terapi kanker antara lain: meminimalkan penggunaan jarum, menggunakan cara yang sederhana, penggunaan jarum yang steril serta melakukan evaluasi setiap melakukan terapi.

Saputra (2002) juga menyatakan bahwa, autism dapat diatasi dengan terapi akupuntur. Dalam pengobatan akupuntur, autism termasuk golongan Minimal Brain Syndrome atau Minimal Brain Disorder. Saat ini, belum ada kesepakatan yang jelas penyebab autisme. Tapi biasanya dikaitkan dengan beberapa faktor seperti: genetik, disfungsi imunologi, kelainan metabolisme, kelainan sistem pencernaan, imunisasi, lingkungan, gangguan masa kehamilan atau persalinan serta infeksi. Adapun kasus- kasus yang dapat diobati dengan cara akupunktur ini antara lain: asthma bronciale, bell's palsy (kelumpuhan saraf otot wajah), cholera, cervical sindrom, Diabetes Melitus, Glaucoma, Colitis Ulcerativa, Hemiplegia-hemiparese (kelumpuhan sebagian anggota gerak), Hemorhoid, Hipertensi, Hyperthyroidysme, Impotensi, Induksi partus (persalinan), insomnia (susah tidur), Ischialgia (nyeri bagian pinggang), Ketergantungan Obat, Leukorrhea, Lumbago, Malaria, Obesitas, Migraine, Trigeminal Neuralgia, Rhinitis Allergica, Ulcus Pepticum dan Tuli (Kusuma \& Kiswojo, 1978:273).

\section{Teknik Akupuntur}

Berbagai jenis terapi akupuntur berkembang dari terapi akupuntur dasar, yaitu 1). Akupuntur hidung; 2). Akupuntur kepala; 3). Akupuntur muka; 4). Akupuntur tangan; 5). Akupuntur cara akebane; 6). Akupuntur cara baru; 7). Terapi pengikatan titik akupuntur; 8). Terapi penyuntikan titik akupuntur. Jenis terapi akupuntur $1 \mathrm{~s} / \mathrm{d}$ 4 adalah sejenis akupuntur telinga, dimana daerah letak titik akupuntur yang mempengaruhi organ jaringan tubuh adalah organ tertentu yaitu: telinga pada akupuntur telinga, hidung pada akupuntur hidung, kepala pada akupunktur kepala, muka pada akupunktur muka dan tangan pada akupunktur tangan (Saputra, 2005). Terapi jenis ini umumnya digunakan dalam ilmu kedokteran barat dalam penegakan diagnose. Namun pengetahuan teori fisiologi organ tetap dibutuhkan. Terapi akupunktur jenis ini, selain digunakan untuk terapi, juga digunakan dalam bidang anastesi sebagai akupunktur analgetik (penghilang rasa sakit) (Kusuma \& Kiswojo, 1978:212).

Untuk mencapai kesimbangan yin dan yang dalam tubuh, titik akupuntur memusatkan energi vital dan sekaligus merupakan tempat untuk menusukkan jarum. Terdapat tiga titik untuk melakukan akupuntur, yaitu: 1) titik umum merupakan titik akupuntur yang terletak pada jalur meridian umum dan istimewa; 2) titik ekstra merupakan titik akupuntur yang terletak pada luar jalur meridian umum dan istimewa; 3) titik nyeri merupakan titik yang bukan termasuk titik meridian umum dan istimewa, dimana jika dilakukan penekanan pada titik tersebut akan menimbulkan rasa nyeri.

Terdapat 12 organ dalam ilmu akupuntur, dimana enam organ berkarakter yin dan enam organ lainnya berkarakter yang (Dharmojono, 2001). Organ cang adalah organ berkarakter yin, sedangkan organ fu adalah organ berkarakter yang, sehingga organ dalam tersebut dinamakan cang fu. Organ cang fu terdiri dari: organ chang : Jantung $($ Hearth= HT), Paru-paru (Lung= LU), Hearth capsule $(\mathrm{HC})$, Hati (Liver = LR), Ginjal $($ Kidney = KI), Perikardium $($ PC) Limpa $($ Spleen $=$ SP). Organ fu: Usus 
Bali Medika Jurnal.

Vol 8 No 1, 2021: 1-12

DOI: https://doi.org/10.36376/bmj.v8i1

kecil $($ small intestine $=\mathrm{SI})$, Usus besar (large intestine $=\mathrm{LI})$, Lambung $($ stomach $=$ $\mathrm{ST})$, Kandung kemih (bladder $=\mathrm{BL})$, Kantung empedu ( gall blader $=$ GB).

Nomenklatur tentang anjuran dan larangan penggunaan akupunktur berdasarkan standarisasi WHO yang disebut sebagai "Proposed Standart International Acupuncture Nomenclature”. Dokumen tersebut mencantumkan halhal sebagai berikut: a. Indikasi pengobatan akupunktur yaitu 1). Saluran nafas: berbagai radang yang ditujukan untuk mengatasi kondisi alergi dan meningkatkan daya tahan tubuh; 2). Mata: radang dan kelainan fungsio otot dan refraksi; 3). Mulut: mengurangi rasa nyeri dalam pencabutan dan peradangan kronis; 4). Saluran makanan dan lambung: berbagai kelainan fungsional yaitu otot, ekskresi asam lambung, nyeri dan peradangan; 5). Syaraf, otot dan tulang, yaitu mengurangi rasa nyeri dan peradangan persendian. Kontra-indikasi pengobatan akupunktur yaitu 1). Penderita dalam keadaan hamil; 2). Memakai alat pacu jantung; 3). Melakukan penusukan di dekat daerah yang terdapat tumor ganas; 4). Melakukan penusukan pada bagian kulit tubuh yang mengalami peradangan (Saputra, 2005).

\section{Faktor-Faktor Yang Mempengaruhi Kepercayaan}

Fator-faktor yang mempengaruhi tingginya minat masyarakat dalam pada pengobatan alternatif menurut Zulkifli (2005) yaitu: 1. Faktor Sosial, keluarga dapat menemani, menjenguk dan menunggui saat proses pengobatan alternatif dilakukan adalah salah satu alasan masyarakat memilih pengobatan alternatif. Sesuai dengan kodratnya, manusia adalah makhluk sosial yang selalu ingin berinteraksi langsung dengan keluarganya atau kerabatnya dalam keadaan sakit. Selama perawatan yang dialaminya mereka dapat berkomunikasi dengan akrab dengan keluarganya. Namun ada juga informasi yang mengemukakan bahwa masyarakat lebih senang dirawat di rumah sakit daripada dirawat di tempat pengobatan alternatif. Mereka melakukan pengobatan alternative karena keterbatasan biaya pengobatan. Ini biasanya dialami oleh pasien yang belum pernah melakukan pengobatan di rumah sakit, sehingga tidak dapat membandingkan khasiat dari pengobatan alternatif dan pengobatan di rumah sakit. Tampak adanya keterbatasan interaksi sosial yang dialami pasien karena keterbatasan pengalamanpengalaaman berobat di tempat layanan kesehatan. 2. Faktor Ekonomi, pengobatan alternatif memerlukan biaya yang lebih murah dibandingkan dengan perawatan di rumah sakit, sehingga masyarakat banyak yang memilih pengobatan alternatif. Selain itu bagi yang tidak mampu membayar sekaligus dapat dicicil setelah pulang. Faktor ekonomi memiliki pengaruh terhadap pemilihan tempat pengobatan. Pasien yang dating ke pengobatan alternative, jika dilihat dari pekerjaan, sebagian besar adalah buruh kasar, tukang parkir dan sopir. 3. Faktor Budaya Pengobatan alternatif dilakukan oleh seorang ahli yang memiliki kekuatan supranatural, sehingga mampu mempercepat proses penyembuhan penyakit. Hal ini merupakan salah satu alasan lebih banyak pasien memilh pengobatan alternatif. Salah satu bagian integral dari kebudayaan adalah sistem medis (Foster \& Anderson, 1986). Faktor lainnya yaitu adanya kepercayaan tentang siapa yang berhak menyembuhkan penyakit tertentu, misalnya untuk penyakit $C$ hanya $D$ yang berhak, penyakit A hanya B yang tepat menyembuhkan. Dalam persepsi masyarakat juga menganggap penyakit yang tidak parah tidak perlu dibawa ke rumah sakit, karena penyakit yang diderita dianggap tidak mengancam jiwanya, 
tidak menggangu nafsu makan serta masih mampu melakukan kegiatan sehari-hari walaupun agak terganggu; 4. Faktor Psikologis, manusia merupakan makhluk biopsiko-sosio-kulutural-spiritual, dan unsur-unsur ini saling mempengaruhi. Proses mental yang abnormal maupun normal dan pengaruhnya pada perilaku merupakan pendekatan psikologis (Departemen Pendidikan Nasional, 2005). Kebutuhan akan hal tersebut menurut Kessler \& Rees L dalam Turana (2009) dapat dipenuhi oleh pengobat alternatif sehingga pasien lebih dapat mengontrol penyakitnya. Aspek psikologis akan mempengaruhi emosi yang berpengaruh erat pada keadaan jasmani (Notoatmodjo, 2007). Sakit adalah kondisi yang tidak nyaman dan menyenangkan. Pasien akan menjalani berbagai cara agar dapat sembuh dan meringankan sakitnya. Salah satunya adalah datang ke pelayanan pengobatan alternatif (Foster \& Anderson, 1986). Kenyamanan diperoleh pada saat pengobatan karena tidak menggunakan peralatan yang menyakitkan (Notoatmodjo, 2007); 5. Faktor Kejenuhan pada Pelayanan Medis. Pengobatan medis memerlukan waktu yang lama. Hal ini menyebabkan penderita merasa bosan berperan sebagai pasien dan ingin segera berakhir dengan kesembuhan. Hal ini sering menyebabkan pasien beralih ingin menjalani alternative pengobatan yang lain, agar proses penyembuhannya dapat lebih cepat atau dengan tujuan meringankan rasa sakit yang diderita (Foster \& Anderson, 1986). Menurut Turana (2009) dasar ilmiah bukan merupakan suatu hal yang penting jika dilihat dari sudut pandang pasien. Biasanya pasien telah menjalani pengobatan konvensional yang tidak dapat mempercepat penyembuhan penyakitnya, sehingga beralih untuk mencoba pengobatan alternatif 6. Faktor Pengetahuan, pengetahuan merupakan hasil dari "tahu" dan ini terjadi setelah orang melakukan penginderaan terhadap suatu objek tertentu. Pengetahuan manusia sebagian besar diperoleh melalui mata, telinga atau kognitif yang merupakan hal yang sangat penting untuk membentuk tindakan seseorang (Notoatmodjo, 2003). Pengetahuan merupakan segala sesuatu yang diketahui oleh seseorang yang didapat secara formal dan informal. Pengetahuan formal diperoleh dari pendidikan sekolah sedangkan pengetahuan informal diperoleh dari media informasi yaitu media cetak seperti majalah, buku, surat kabar, serta media elektronika seperti radio, televisi dan internet (Purwanto, 1996).

\section{Teori mengenai faktor-faktor yang mempengaruhi kepercayaan}

Menurut Green, perilaku dipengaruhi oleh tiga faktor utama, yakni : 1. Faktor-faktor perdisposisi (predisposing factors): tingkat pendidikan, sosial ekonomi, pengetahuan dan sikap masyarakat terhadap kesehatan, sistem nilai yang dianut oleh masyarakat, hal-hal yang berkaitan dengan kesehatan, tradisi dan kepercayaan masyarakat dan lain sebagainya. Untuk dapat melakukan pemeriksaan kesehatan dengan baik, masyarakat memerlukan pengetahuan dan kesadaran tentang manfaat memeriksakan kesehatan, yaitu demi kelangsungan dan usia harapan hidupnya. Selain itu, faktor pendorong dan penghambat bagi masyarakat untuk memeriksakan kesehatan adalah tradisi, kepercayaan dan sistem nilai masyarakat. Beberapa faktor tersebut sering disebut faktor pemudah, karena memberikan hal-hal positif yang mewujudkan perubahan perilaku. 2. Faktorfaktor pemungkin (enabling factors) Hal-hal yang termasuk dalam faktor pemungkin antara lain: fasilitas pelayanan kesehatan seperti rumah sakit, dokter atau bidan praktik swasta, puskesmas, poliklinik, polindes, posyandu, pos obat desa 
Bali Medika Jurnal.

Vol 8 No 1, 2021: 1-12

DOI: https://doi.org/10.36376/bmj.v8i1

dan sebagainya. Ketersediaan sarana dan prasarana dan fasilitas kesehatan, misalnya: ketersediaan makanan yang bergizi, air bersih, tempat pembuangan sampah, tempat pembuangan tinja dan sebagainya. Diperlukan sarana dan prasarana pendukung untuk berperilaku sehat, misalnya: perilaku pemeriksaaan kesehatan pada masyarakat. Untuk melakukan pemeriksaan kesehatan pada masyarakat, selain tahu dan sadar manfaat pemeriksaan kesehatan, masyarakat juga harus dapat dengan mudah mengakses fasilitas dan layanan pemeriksaan kesehatan, misalnya : puskesmas, polindes, bidan praktik ataupun rumah sakit. Fasilitas merupakan faktor pendukung atau pemungkin terwujudnya perilaku kesehatan, karena pada hakekatnya berfungsi untuk mewujudkan perubahan perilaku kesehatan pada masyarakat. 3. Faktor-faktor penguat (reinforcing factors) Faktor-faktor ini meliputi sikap dan perilaku para petugas kesehatan, sikap dan perilaku tokoh masyarakat (toma) dan tokoh agama (toga). Termasuk juga disini undang-undang, peraturan-peraturan baik dari pusat maupun pemerintah daerah yang terkait dengan kesehatan. Pengetahuan, sikap positif dan dukungan fasilitas saja terkadang bukan merupakan hal yang paling diperlukan dalam masyarakat untuk berperilaku sehat. Model/percontohan dari para petugas kesehatan, para tokoh masyarakat dan tokoh agama merupakan perilaku acuan (model) bagi masyarakat. Peraturan perundangundangan sangat diperlukan dalam memeprkuat perilaku kesehatan masyarakat. Sebagai contoh dalam perilaku pemeriksaan kesehatan, diperlukan kemudahan dalam memperoleh layanan pemeriksaan kesehatan serta diperkuat dengan peraturan perundang-undangan yang mengharuskan masyarakat untuk melakukan pemeriksaan kesehatan secara rutin terutama yang memiliki riwayat penyakit kronis (Notoatmodjo, 2003).

\section{METODE PENELITIAN}

Metode kualitatif adalah metode yang digunakan dalam penelitian ini, dimaan peneliti ingin melihat faktor internal dan eksternal yang dapat membentuk kepercayaan masyarakat untuk melakukan pengobatan komplementer akupuntur di Praktik Perawat Mandiri Latu Usadha Abiansemal Badung. Instrumen yang digunakan adalah pedoman wawancara mendalam. Adapun lokasi pada penelitian ini yaitu Praktik Perawat Mandiri Latu Usadha Abiansemal Badung yang terletak di Jalan Raya Gerih No. 84 Kecamatan Abiansemal, Kabupaten Badung, Bali. Studi pendahuluan dilaksanakan pada tanggal 15 Agustus 2019. Pelaksanaan penelitian dimulai pada bulan Maret - Mei 2020. Wawancara mendalam dengan pasien dilaksanakan pada tanggal 13 s/d 28 Mei 2020, sedangkan wawancara mendalam dengan tiga orang perawat diaksanakan selama dua hari yaitu tanggal 2 dan 4 Mei 2020 .

Penelitian ini menggunakan data primer yaitu data yang diperoleh dan dikumpulkan secara langsung dari informan pada satu waktu tertentu dengan menggunakan pedoman wawancara. Cara memperoleh data sekunder adalah dengan melihat buku registrasi pasien. Informan pada penelitian ini adalah pasien yang sedang melakukan terapi komplementer akupuntur dengan jumlah 10 orang. Informan dipilih secara acak (randomisasi). Untuk menilai pengalaman informan, peneliti menggunakan skala likert yaitu mengelompokan menjadi pengalaman kurang baik: 1-9, cukup baik: 10-19, sangat baik: 20-28. 


\section{HASIL DAN PEMBAHASAN}

\section{Gambaran Umum Klinik Latu Usadha}

Latu Usadha merukapan sebuah tempat praktik Keperawatan Holistik yang beralamat di J1. Raya Gerih No.84, Abiansemal, Kecamatan Abiansemal, Kabupaten Badung, Bali. Tenaga kesehatan yang melayani pasien dalam memberikan terapi komplementer akupuntur yaitu perawat yang saat mengikuti pendidikan dikampus memilih peminatan komplementer dan sudah mendapatkan pelatihan selama tiga bulan sebelum menangani pasien. Klinik ini memiliki tiga orang perawat jaga dengan dua shift yaitu pagi dan sore. Pelayanan yang diberikan merupakan pelayanan holistik yaitu penggabungan antara pelayanan medis dan komplementer, selain memberikan terapi komplemneter, pasien juga akan diberikan obat medis sesuai kebutuhan pasien, misalnya penghilang nyeri. Pasien diberikan terapi dengan durasi kurang lebih 40 menit. Dalam menentukan terapi, pasien akan berkonsultasi dengan perawat jaga, setelah itu terapi yang sesuai akan diberikan oleh perawat jaga sesuai dengan keluhan pasien, baik itu bekam, akupuntur maupun akupresur.

\section{Karakteristik Informan}

Pasien yang berobat ke klinik Latu Usadha ini tidak hanya berasal dari masyarakat sekitar, namun juga ada yang berasal dari kabupaten Jembrana, dimana pasien membutuhkan waktu tiga jam untuk sampai di klinik ini. Pekerjaan pasien pun beraneka ragam, dari pedagang, pegawai bahkan dokter datang ke klinik ini untuk mendapatkan terapi komplemnetr akupuntur. Beberapa pasien yang melakukan terapi komplementer akupuntur menggabungkan metode pengobatannya dengan metode pengobatan medis. Usia pasien yang melakukan terapi komplementer akupuntur yaitu sebagain besar dalam rentang usia 40-55 tahun, jenis kelamin sebagian besar laki-laki.

\section{Gambaran Pengalaman Informan Mendapat Terapi Komplementer Akupuntur}

Tabel 1 di bawah ini akan menjelaskan pengalaman informan saat mendapatkan terapi komplementer akupuntur di Praktik Perawat Mandiri Latu Usadha Abiansemal.

Tabel 1.

Pengalaman Informan Dalam Mendapatkan Terapi Komplementer Akupuntur

\begin{tabular}{cccc}
\hline $\begin{array}{c}\text { N } \\
\text { o }\end{array}$ & $\begin{array}{c}\text { Informa } \\
\text { n }\end{array}$ & Skor & Kategori \\
\hline 1 & IN-01 & 28 & Sangat Baik \\
2 & IN-02 & 25 & Sangat Baik \\
3 & IN-03 & 20 & Sangat Baik \\
4 & IN-04 & 19 & Cukup Baik \\
5 & IN-05 & 18 & Cukup Baik \\
6 & IN-06 & 22 & Sangat Baik
\end{tabular}


Bali Medika Jurnal.

Vol 8 No 1, 2021: 1-12

ISSN : 2615-7047

DOI: https://doi.org/10.36376/bmj.v8i1

\begin{tabular}{cccc}
7 & IN-07 & 24 & Sangat Baik \\
8 & IN-08 & 24 & Sangat Baik \\
9 & IN-9 & 26 & Sangat Baik \\
10 & IN-10 & 28 & Sangat Baik \\
\hline
\end{tabular}

Tabel 1 di atas menunjukan bahwa sebagian besar informan memiliki pengalaman yang sangat baik terhadap pengobatan akupuntur, kecuali informan 4 dan 5 yang memiliki pengalaman cukup baik karena masih merasakan nyeri, ngilu dan reaksi lokal lainnya setelah terapi.

\section{Faktor Internal Yang Mendukung Informan Melakukan Terapi Komplementer Akupuntur}

Data primer menunjukan terdapat tiga faktor yang mendukung informan melakukan terapi komplementer akupuntur yaitu faktor kepercayaan/ tradisi, persepsi dan pengetahuan. Persepsi merupakan suatu proses yang dijalani oleh individu dalam menginterpretasikan dan mengatur kesan - kesan sensori sehingga memberikan arti bagi lingkungan mereka (Robbins dan Judge, 2008). Pengetahuan merupakan hasil dari "tahu" dan ini terjadi setelah orang melakukan penginderaan terhadap suatu objek tertentu.

Pengetahuan manusia sebagian besar diperoleh melalui mata dan telinga atau kognitif. Hal ini sangat penting dalam pembentukan tindakan seseorang (Notoatmodjo, 2003). Hampir sebagian besar informan menyatakan faktor kepercayaan, persepsi dan pengetahuan menjadi faktor internal untuk mereka melakukan akupuntur, seperti kutipan di bawah ini:

“....menurut pandangan saya akupuntur ini terapi yang sangat pas untuk saya, pokoknya saya nyaman, yaa... pokoknya saya sangat cocok dengan penyakit saya.”, $\mathrm{IN}-02$

"......karena sugesti kali ya dik, dipegang dikit aja sama bapak ibu disini, Astungkara mau dia lebih baik sakit saya”, IN-09

“......saya pernah baca di internet, sebaiknya memang kalau kita mau sehat maksimal, kita sebaiknya pengobatan kita dikombain, ya medis oke, tradisional juga oke", IN-06

".... di keluarga saya memang begitu, kalau obat dokter ditambah tradisional pasti cepet sembuh", IN-08

Menurut Setyaningsih (2012) menunjukan bahwa terdapat hubungan positif antara persepsi dengan sikap masyarakat melakukan pengobatan komplementer. Hasil penelitian ini juga sesuai dengan penelitian Kamaluddin (2010), menunjukan bahwa adanya interaksi personal klien dengan praktisi membangun kepercayaan masayarakat untuk melakukan terapi komplementer. Dari penelitian ini ditemukan bahwa persepsi dan kepercayaan sangat mempengaruhi informan dalam melakukan akupuntur.

\section{Faktor Eksternal Yang Mendukung Informan Melakukan Terapi Komplemneter Akupuntur}

Faktor ekonomi, kebudayaan, pekerjaan, penghasilan, dukungan keluarga merupakan faktor eksternal yang dapat berpengaruh terhadap kepercayaan masyarakat dalam melakukan pengobatan komplementer akupuntur. 
Bali Medika Jurnal.

Vol 8 No 1, 2021: 1-12

ISSN : 2615-7047

DOI: https://doi.org/10.36376/bmj.v8i1

“....kalau berobat di dokter terus mahal banget bu,gak kuat bayarnya”, IN-01

“....kalau di Bali kan memang begitu ya, gak lengkap kalau gak berobat tradisonal",IN-04

“....masalah waktu ya, kalau berobat seperti ini kan bisa habis bekerja, gak saklek kayak di dokter", IN-07

“...kalau beli obat dokter terus, habis gaji saya dik, hahahahaha" IN-06

“...keluarga juga nyaranin saya kesini, karena dilihat tetangga juga kesini sembuh dia”, IN-10.

Menurut Krisnawati (2012), menunjukkan bahwa faktor ekonomi menjadi penting dalam pengambilan keputusan tempat pengobatan yang murah, efektif dan manjur. Penelitian ini sesuai dengan teori yang menunjukan bahwa selain budaya dan dukungan keluarga, ekonomi dan penghasilan menjadi faktor penting dalam memilih tempat berobat para informan.

\section{Hambatan yang Dialami Informan}

“....ya paling klinik dengan rumah saya jaraknya jauh, tapi itu gak masalah”, IN03

“..ada kok yang jauh dari Negare pasiennya, tapi tetep semangat berobat ke sini”, Per-01

Hal ini sesuai dengan penelitian sebelumnya, dimana menurut Supriadi (2014), menunjukan bahwa jarak dari rumah informan menuju ke tempat pengobatan tradisional tidak memiliki hubungan signifikan terhadap pengambilan keputusan masyarakat dalam memilih pengobatan tradisonal. Dari paparan salah satu perawat yang diwawancara menyatakan bahwa hambatan yang muncul adalah jarak yang jauh, namun hal itu tidak menjadi permasalahan yang bermakna dari pasien dan belum ada pasien yang menghentikan pengobatan karena kendala jarak. Pasien yang jarak rumahnya jauh tetap tertib dalam melakukan pengobatan.

\section{SIMPULAN DAN SARAN}

Gambaran kepercayaan masyarakat dalam melakukan pengobatan akupuntur di Klinik Latu Usadha sangat baik, dimana kepercayaan ini timbul karena dipengaruhi faktor internal yaitu faktor kepercayaan/tradisi, persepsi dan pengetahuan, serta faktor eksternal yaitu faktor ekonomi, kebudayaan, pekerjaan, penghasilan, dukungan keluarga. Faktor yang paling dominan adalah faktor ekonomi dan penghasilan.

Upaya promosi dan pengembangan pelayanan kesehatan komplementer khususnya akupuntur bisa dilakukan lebih efektif dan inovatif lagi, sehingga masyarakat yang sudah terbuka dengan informasi dapat mengetahui serta dapat memilih pelayanan kesehatan yang akan digunakan pada saat mengalami gangguan. Keterbatasan yang muncul dalam penelitian ini adalah pembatasan interaksi dengan pasien karena terkendala dengan pandemi Covid-19, sehingga pelaksanaan wawancara sebagian besar dibantu oleh perawat yang bertugas di Klinik Latu Usadha. 


\section{UCAPAN TERIMA KASIH}

Kami mengucapkan terimakasih yang sebesar-besarnya kepada seluruh pihak di Praktik Perawat Mandiri Latu Usadha Abiansemal Badung atas segala fasilitas dan bantuan selama pelaksanaan penelitian ini. Tidak lupa pula kami haturkan terimakasih kepada seluruh informan yang telah bersedia meluangkan waktu untuk berbagi informasi yang kami butuhkan dalam penelitian ini. Semoga hasil penelitian ini dapat bermanfaat bagi pengembangan ilmu pengetahuan terutama dalam bidang kesehatan.

\section{DAFTAR PUSTAKA}

Departemen Pendidikan Nasional. (2005). Kamus Besar Bahasa Indonesia. Jakarta: Balai Pustaka.

Dharmojono. (2001). Menghayati Teori \& Praktek Akupunktur \& Moksibasi. Jakarta: Trubus Agriwidya.

Foster, \& Anderson. (1986). Antropologi Kesehatan. Jakarta: UI Press.

Kamaluddin, R. (2010). Pertimbangan dan Alasan Pasien Hipertensi Menjalani Terapi Alternatif Komplementer Bekam di Kabupaten Banyumas. Jurnal Keperawatan Soedirman, 5(2), 95-104. Retrieved from http://jks.fikes.unsoed.ac.id/index.php/jks/article/view/276/151

Kementerian Kesehatan Republik Indonesia. Peraturan Menteri Kesehatan Republik Indonesia nomor 37 tahun 2017 tentang Pelayanan Kesehatan Tradisional Integrasi. , (2017). Indonesia.

Krisnawati, A. (2012). Faktor-Faktor yang Mempengaruhi Kunjungan Pasien di Klinik Alternatif Akupuntur Yogyakarta Tahun 2012 (Sekolah Tinggi Ilmu Kesehatan 'Aisiyah Yogyakarta). Sekolah Tinggi Ilmu Kesehatan 'Aisiyah Yogyakarta. Retrieved from http://digilib.unisayogya.ac.id/1479/1/NASKAH PUBLIKASI_ATUN KRISNAWATI

Kusuma, A., \& Kiswojo. (1978). Teori dan Praktek Ilmu Akupunktur. Jakarta: Gramedia.

Notoatmodjo, S. (2003). Ilmu Kesehatan Masyarakat. Jakarta: Rineka Cipta.

Notoatmodjo, S. (2007). Prinsip - Prinsip Dasar Promosi Kesehatan \& Ilmu Perilaku. Jakarta: Rineka Cipta.

Purwanto, N. (1996). Psikologi Pendidikan. Bandung: Remaja Rosdakarya.

Saputra, K. (2002). Akupunktur Klinik. Surabaya: Airlangga Press.

Saputra, K. (2005). Akupunktur Dasar. Surabaya: Airlangga University Press.

Saputra, K. (2012). Akupunktur dalam Pelayanan Kesehatan tingkat Rumah Sakit. OPINI, 39(10), 780-782. 
Setyaningsih, Y. (2012). Hubungan Antara Persepsi dengan Sikap Masyarakat Terhadap Pengobatan Komplementer di Kecamatan Grogol Kabupaten Sukoharjo. Universitas Muhammadiyah Surakarta.

Sukanta, P. O. (2008). Pijat Akupresure untukKesehatan. Jakarta: Penebar Plus.

Supriadi. (2014). Determinan Perilaku Pencarian Pengobatan Tradisional (Tradisional Medication) Masyarakat Urban Cengkareng Jakarta Barat Tahun 2014. Universitas Islam Negeri Syarif Hidayatullah.

Turana, Y. (2009). Seberapa Besar Manfaat Pengobatan Alternatif. Retrieved February 10, 2020, from medikaholistik website: www.medikaholistik.com

Windridge, C. (1999). Tong Sing The Chinese Book of Wisdom. London: 122 Arlington.

Zulkifli. (2005). Pengantar Studi Ilmu Administrasi dan Manajemen. Pekanbaru: UIR Press. 